\title{
ALTAS HABILIDADES OU SUPERDOTAÇÃO E EDUCAÇÃO SUPERIOR: UM ESTUDO DE CASO
}

\author{
Amabriane da Silva Oliveira Shimite* \\ Nilson Rogério da Silva** \\ Fabiana Oliveira Koga $a^{* * *}$
}

\begin{abstract}
RESUMO: Com o intuito de estudar o fenômeno das Altas Habilidades ou Superdotação (AH ou SD) buscou-se analisar a experiência de acesso à Educação Superior por um estudante com AH ou SD, em um estudo de caso. A coleta dos dados foi realizada por meio de entrevista semiestruturada e a análise dos dados, pelo procedimento da análise da configuração textual. Na fala do estudante com AH ou SD foi possível observar as interferências da condição socioeconômica e familiar em seu desenvolvimento, além da ânsia pelo conhecimento e a busca por melhores oportunidades de estudo. A superação das dificuldades relatadas pelo estudante foi evidenciada pela inteligência emocional e a capacidade acadêmica, demonstradas em seu senso de lógica e objetividade. $\mathrm{O}$ acesso à Educação Superior foi conquistado por meio da consciência, resiliência, paciência e transgressão. A ausência de acolhimento, da identificação de estudantes com AH ou SD e das condições de permanência na Educação Superior foram enfatizadas como barreiras para uma trajetória de formação profissional, que valoriza o desenvolvimento humano.
\end{abstract}

PALAVRAS-CHAVE: Educação Superior; Altas Habilidades; Superdotação; Inclusão.

\section{HIGH ABILITIES OR GIFTEDNESS AND HIGHER EDUCATION:}

\section{A CASE STUDY}

\begin{abstract}
In order to study the phenomenon of High Abilities or Giftedness, we sought to analyze the experience of access to Higher Education by a student with High Abilities or Giftedness, in a case study. Data collection was carried out through semi-structured interviews and data analysis through the textual configuration analysis procedure. In the speech of the student with High Abilities or Giftedness, it was possible to observe the interference of socioeconomic and family conditions in his development, in addition to the eagerness for knowledge and the search for better study opportunities. Overcoming the difficulties reported by the student was evidenced by emotional intelligence and academic ability, demonstrated in his sense of logic and objectivity. Access to Higher Education was achieved through awareness, resilience, patience and transgression. The lack of reception, the identification of students with High Abilities or Giftedness and the conditions of permanence in Higher Education were emphasized as barriers to a trajectory of professional training, which human development is valued.
\end{abstract}

KEYWORDS: Higher Education; High Abilities; Giftedness; Inclusion.

\footnotetext{
* Mestre em Educação pela Universidade Estadual Paulista (UNESP), doutoranda em Educação pela Faculdade de Filosofia e Ciência - UNESP/ Marília-SP e bolsista de pesquisa pela Coordenação de Aperfeiçoamento de Pessoal de Nível Superior CAPES. E-mail: dsshimite@gmail.com. ORCID: 0000-0003-1523-7097.

** Doutor em Educação Especial pela Universidade Federal de São Carlos (UFSCAR), Professor Associado ao curso de Terapia Ocupacional e ao Programa de Pós-Graduação em Educação da Universidade Estadual Paulista (UNESP). E-mail: nilson.silva@unesp.br. ORCID: 0000-0002-8866-0964.

*** Doutora em Educação pela Universidade Estadual Paulista (UNESP), Professora do curso de Pedagogia da Faculdade do Interior Paulista (FAIP). E-mail: fabianapsicopedagogiamusical@gmail.com. ORCID: 0000-0002-4646-1537.
} 


\section{Introdução}

Quem nunca se deparou com pessoas, que foram capazes de realizar grandes criações e performances? Em alguns casos, essas pessoas podem causar espanto dada sua capacidade de internalização rápida da cultura, do conhecimento e da apresentação de perspectivas inovadoras para a sociedade. Esse fenômeno que coloca tal pessoa em evidência é denominado pela legislação brasileira como Altas Habilidades ou Superdotação (AH ou SD) ${ }^{1}$.

Para Renzulli (2014) as AH ou SD podem se desenvolver em certas pessoas, em determinados momentos e circunstâncias da vida. O ambiente social e econômico tem grande importância, uma vez que essa pessoa com $\mathrm{AH}$ ou SD necessita de oportunidade, engajamento e encorajamento para se desenvolver.

Ademais, na perspectiva de Renzulli (2014), esse fenômeno se divide em dois espectros: a superdotação acadêmica e a superdotação criativo-produtiva. O primeiro tipo está relacionado àquelas pessoas que se destacam em testes de Quociente de Inteligência (QI) ou em decorrência de sua performance acadêmica. Essas pessoas apresentam alto desempenho em matérias ou conhecimentos escolares, aprendem rápido e são capazes de atingir altas pontuações em olímpiadas do saber, competições e até na própria escola ou universidade. Além do rápido aprendizado de determinada lição ou conceito, a reprodução ocorre em alto nível. O segundo tipo é mais complexo, porque geralmente podem não se destacar em testes de QI e tampouco em ambientes acadêmicos, inclusive, podem apresentar fracasso escolar, desmotivação, problemas emocionais (DABROWSKI, 2017) e até evadir do sistema educacional em decorrência de não serem atendidas em sua área de interesse ou por não se encaixarem naquele determinado ambiente. Essas pessoas gostam de realizar aquilo que tem relevância pessoal, ou seja, o que faz sentido, o que as interessam e aguça sua curiosidade. Esse tipo tem como ponto crucial a criatividade e/ou inventividade. Para Renzulli (2014), a história mostra que as pessoas criativo-produtivas foram produtoras do conhecimento e deixaram a sua marca na história.

Como forma de designar o fenômeno das Altas Habilidades ou Superdotação, Renzulli (2014; 2018) criou a Teoria dos Três Anéis, apresentando as dimensões do potencial humano para a produtividade criativa. Os anéis são compostos pelas seguintes nuances: 1 - habilidade acima da média, 2 - envolvimento com a tarefa e 3 - criatividade. A primeira é definida pelo autor como a capacidade de adquirir conhecimento e técnicas de modo rápido; a segunda pela capacidade de concentração focada e alta motivação, o investimento de toda a sua energia em determinada atividade, esquecendo-se do mundo a sua volta, apresenta persistência, resiliência, trabalho com afinco etc; a terceira nuance é caracterizada pelo conjunto de traços como: capacidade da inventividade e originalidade, como por exemplo, os

\footnotetext{
${ }^{1}$ O presente termo será adotado ao longo de todo o texto e foi extraído da Lei de Diretrizes e Bases para Educação Nacional - LDBEN no 9394/96 (BRASIL, 1996). Isso porque há muitas terminologias no Brasil e no mundo utilizadas para designar esse fenômeno.
} 
cientistas que usam sua criatividade para prever, analisar e resolver problemas da sociedade de modo inédito. Renzulli $(2014 ; 2018)$ teorizou que a intersecção dos Três Anéis configura o comportamento de Superdotação.

Renzulli (2021) buscando engajar, oportunizar e encorajar pessoas com AH ou SD desenvolveu, também, o Modelo de Enriquecimento para a escola como um todo. Embora não tenha pensado especificamente para as universidades, essa perspectiva possibilitou colaborar com o desenvolvimento de estudantes com $\mathrm{AH}$ ou SD, nos mais diferentes níveis de ensino. O Modelo de Enriquecimento criado por Renzulli (2018; 2021) contempla três tipos: 1 - caracteriza-se por atividades gerais e exploratórias; 2 - envolve o contato com conceitos e instrução, ou seja, com o conhecimento científico, além do treinamento; 3 - caracteriza-se pela etapa de investigação, principalmente, de problemas reais. Nessa etapa são obtidos os produtos finais (concretos/o produto em si ou a elaboração de novos conceitos/avanços teóricos).

Em sua obra, Renzulli e Reis (2014) e Renzulli (2018; 2021) orientam a identificação dessas pessoas e o enriquecimento. Para a identificação Renzulli e Reis (2014) construíram escalas, questionários, roteiros de entrevista e protocolos de observação todos devidamente validados nos Estados Unidos da América. Além disso, organizaram as etapas de enriquecimento orientando como deve ocorrer todo o processo desde a identificação. Renzulli (2021) ao longo de sua trajetória preocupou-se com a identificação e com o desenvolvimento a longo prazo dos estudantes com AH ou SD.

Infelizmente, os instrumentos de identificação no Brasil necessitam de validação, de acordo com Farias e Weschler (2014). Guenther (2011) por exemplo, criou o Modelo Diferenciado de Dotação e Talento (DMGT). Com base em Renzulli (2021) há as escalas como as de Freitas e Pérez (2012), além de pesquisas que traduziram e aplicaram suas escalas no Brasil. No entanto, são pesquisas que não aprofundaram ou apresentaram os dados ou procedimentos de validade como, por exemplo, tem feito Nakano (2014), em artigos científicos da área, no âmbito do rastreamento da criatividade.

O enriquecimento vem ocorrendo, mas ainda de modo incipiente e, por vezes, fora das instituições universitárias e escolares. Seguem alguns exemplos: Centro para o Desenvolvimento do Potencial e Talento (CEDET ${ }^{2}$ ), Núcleos de Atividades de Altas Habilidades/Superdotação (NAAHS) de Londrina/PR ${ }^{3}$ e São Luiz/ MA (Maranhão ${ }^{4}$ ), Projeto Ingenium ${ }^{5}$, Instituto Rogério Sternberg ${ }^{6}$, Smart ${ }^{7}$ e outros. Por outro lado, iniciativas para o enriquecimento de estudantes com AH ou SD na Educação Superior são extremamente escassas, por vezes, apresentando alguns casos pontuais e isolados (LIMA; MOREIRA, 2018).

\footnotetext{
2 https://www.educacao.assis.sp.gov.br/projeto/26/cedet

3 http://www.ldanaahs.seed.pr.gov.br/modules/noticias/

${ }^{4}$ https://www.educacao.ma.gov.br/nucleo-de-altas-habilidadessuperdotacao-completa-10-anos-de-fundacao/

${ }^{5}$ https://www.facebook.com/projetoingenium/

${ }^{6}$ http://www.irs.org.br/

${ }^{7}$ https://www.ismart.org.br/2020/06/altas-habilidades-superdotacao-conheca-nosso-guia-pratico/
} 
A Lei de Diretrizes e Bases para a Educação Nacional - LDBEN no 9394/96 (BRASIL, 1996), reconhece que estudantes com AH ou SD integram a Educação Especial do Ensino Básico ao Superior. Ao serem identificados, devem ser cadastradas na plataforma (censo) do Ministério da Educação e receber atendimento educacional especializado. No caso da Educação Superior, a lei prevê ainda, que o aluno com extraordinário aproveitamento nos estudos, por meio da realização de provas ou outros instrumentos de avaliação, aplicados por uma banca de especialistas, poderá acelerar seus estudos realizando o curso em menor tempo ou, em âmbito da pós-graduação, obter o ingresso no curso de doutorado (BRASIL, 1996).

Basso et al. (2020) destacou em sua pesquisa a dificuldade de obtenção do número de alunos ingressantes na Educação Superior com $\mathrm{AH}$ ou SD, bem como a pequena quantidade de trabalhos que abordam as AH ou SD na vida adulta, principalmente, na Educação Superior. Basso et al. (2020) ainda enfatizaram a necessidade da identificação desse público, pois em sua maior parte, ingressam sem saber que são estudantes com $\mathrm{AH}$ ou $\mathrm{SD}$, bem como não dispõem de acesso a um acompanhamento qualificado para atender as suas necessidades de aprendizagem, com a finalidade de fomentar sua formação profissional, por meio de sua capacidade intelectual e/ou criativa. Oliveira (2020) também ressaltou a lacuna existente na literatura, em relação à identificação como $\mathrm{AH}$ ou $\mathrm{SD}$ de estudantes na Educação Superior.

Nesse contexto, cabe questionar como é o acesso à Educação Superior por um estudante com AH ou SD? Diante da problematização, buscou-se analisar a experiência de acesso à Educação Superior por um estudante com AH ou SD.

Para aprofundarmos a discussão utilizaremos, adicionalmente, os estudos, teorizações e o documento/legislação conforme podemos encontrar em: Rubinstein (1978), Benveniste (1988), Chagas e Fleith (2009), Charandeau (2012), Guenther (2011; 2012), Duarte (2013), Cianca e Marquezine (2014), Chagas-Ferreira (2014), Brasil (2015), Winner (1996) e Oliveira, Rodrigues e Capellini (2020).

\section{Método}

Para o desenvolvimento da pesquisa qualitativa fez-se a opção metodológica pelo Estudo de Caso, devido à busca em identificar os aspectos que envolvem o acesso à Educação Superior por pessoas com AH ou SD. Contudo, esse processo necessita de profundidade analítica e compreensão do contexto em que está inserido o estudante com AH ou SD e por isso, fez-se a opção pela abordagem descritiva. Yin (2010, p.39) define o estudo de caso com "uma investigação empírica de um fenômeno contemporâneo em profundidade e em seu contexto de vida real, especialmente, quando os limites entre o fenômeno e o contexto não são claramente evidentes".

Ao abordar um estudo de caso descritivo, segundo Lüdke e André (1986), propõem-se o contato do pesquisador com o participante e com a situação estudada, de forma direta. Nesse sentido, os autores 
enfatizaram a busca em retratar a perspectiva do participante e, consequentemente, o processo em que está se propondo estudar em profundidade, "por se constituir numa unidade dentro de um sistema mais amplo" (LÜDKE; ANDRÉ, 1986, p.17), possibilitando generalizações sobre o fenômeno estudado.

A pesquisa obteve aprovação do Comitê de Ética em Pesquisa sob CAEE 83247918.0.0000.5406 e parecer $\mathrm{n}^{\circ} 2.550 .198 / 2018$.

\section{Participantes}

O estudante com AH ou SD possui 18 anos, solteiro, residente com sua mãe na cidade onde está localizada a faculdade, sendo filho único. Sua mãe é auxiliar de produção em uma indústria e possui Ensino Médio completo. O participante estava cursando o primeiro ano do curso de graduação, sendo selecionado no primeiro semestre para a bolsa de auxílio estudantil, o que garantiu sua permanência nesse período na faculdade. Alguns meses depois, ingressou em grupos de pesquisas na área de Comércio Exterior e foi selecionado como bolsista de iniciação científica. A bolsa de pesquisa recebida em conjunto com a prestação de serviços como Técnico em Informática garantia a renda do estudante com AH ou SD na Educação Superior.

Em relação à identificação como estudante com AH ou SD, foi realizado contato com o estudante por meio de um programa de extensão universitária, o qual ocorreu nas dependências da faculdade em que eram atendidos alunos indicados ou recomendados por escolas públicas da cidade com indicativos do comportamento AH ou SD. Esse programa integrava as atividades desenvolvidas no Programa de Pós-graduação em Educação, na linha de pesquisa em Educação Especial. Nesse sentido, o estudante era autodeclarado como AH ou SD e por meio dessa ação foi possível identificá-lo e convidá-lo a participar da pesquisa.

\section{Procedimentos e materiais de coleta}

A coleta dos dados ocorreu em uma unidade universitária pertencente a uma instituição de Educação Superior pública do estado de São Paulo, na qual constam cursos de graduação e pósgraduação, em novembro de 2018.

O estudante com $\mathrm{AH}$ ou SD foi contatado via telefone, no qual foi explicado o motivo do contato, o objetivo do convite e foi realizado o pedido para participar da pesquisa. Foram agendados um dia e horário, que melhor atendessem à agenda do participante, destacando a necessidade de ocorrência da coleta de dados no ambiente da faculdade. Essa solicitação foi realizada, devido ao enquadre da entrevista. De acordo com Manzini (2020) a busca pelo sentido do relato do participante em uma entrevista ocorre pela interação participante e pesquisador, mas também pelo enquadramento social e por esse motivo, esse deve ser o mais próximo do fenômeno a ser pesquisado. 
O procedimento utilizado para a coleta de dados foi a entrevista semiestruturada, na qual fez-se a aplicação de um roteiro de entrevista elaborado, avaliado por juízes e testado em projeto piloto, conforme as recomendações de Manzini (2020). A escolha pela entrevista semiestrutura ocorreu devido à necessidade da busca da fala do estudante com AH ou SD, de sua avaliação sobre essa experiência de acesso a Educação Superior e quais aspectos seriam considerados importantes nessa trajetória, mediante a avaliação do estudante com AH ou SD. De acordo com Manzini (2020, p.23) “a fala é a expressão daquela informação que o entrevistador busca no discurso do entrevistado”. Nesse sentido, optou-se pelo procedimento de entrevista semiestruturada para a coleta dos dados, por constituir um processo de interação social entre um pesquisador com objetivo definido, que por meio da linguagem, busca informações sobre determinado fenômeno (MANZINI, 2020).

Para a realização da entrevista foi utilizado um gravador para registro de áudio. Na data agendada, o estudante com AH ou SD foi encaminhado para uma sala de aula na faculdade. Ao chegar foi recebido pelos pesquisadores e informado de como seria a entrevista, sendo entregue o Termo de Consentimento Livre e Esclarecido (TCLE). O estudante com AH ou SD fez a leitura do termo, sendo enfatizado pelos pesquisadores o objetivo da pesquisa, o procedimento da entrevista e o pedido de sua permissão para a gravação de áudio. Após o aceite do participante, os primeiros dez minutos foram para abertura do diálogo, adequação do equipamento e descontração. Quando iniciada a gravação, o participante foi informado que a entrevista teria início e assim, foram sendo realizadas as questões contidas no roteiro de entrevista. A entrevista teve duração de uma hora e quarenta minutos.

Após a entrevista semiestruturada, as informações concedidas foram transcritas de acordo com as normas de Marcuschi (1986) e Manzini (2020).

\section{Análise dos dados}

Os dados foram analisados buscando identificar a construção social da fala e em consequência, o discurso do estudante com AH ou SD sobre a Educação Superior. Contudo, o discurso é uma construção social maior e que possui aspectos do pensamento e da linguagem, que corroboram com a compreensão do indivíduo na e sobre a sociedade. Por esse motivo, determinamos analisar a fala do estudante com AH ou SD no momento de seu ingresso na Educação Superior, pois buscou-se compreender o pensamento e suas interligações na fala com o momento em que estava vivendo. Vigotski (1989) destaca que é preciso entender mais do que a palavra, sendo necessário compreender a fala para poder entender o pensamento. Contudo, isso não é suficiente porque se faz necessário identificar o motivo e o contexto em que determinados enunciados são construídos. Nesse sentido, Souza (2014, p.6) enfatiza que "nada na fala é aleatório" e por isso, o discurso resulta da interação entre sujeitos localizados no tempo em condições históricas, sociais e ideológicas. 
A análise empregada aos dados coletados foi a Análise da Configuração Textual proposta por Mortatti (2000), que busca no texto os aspectos inter-relacionados e investigativos para a compreensão do sentido do texto e do questionamento de que não existem discursos puros. A Análise da Configuração Textual é composta por um conjunto de aspectos característicos, sendo esses:

[...] as opções temático - conteudísticas (o quê?), estruturais formais (como?), projetadas por um determinado sujeito (quem?), se apresenta como autor de um discurso produzido de determinado ponto de vista e lugar social (de onde?), em um momento histórico (quando?), movido por certas necessidades (por quê?), com propósito (para quê?), visando a determinado efeito (para quem?) e logrado em determinado tipo de circulação, utilização e repercussão (MORTATTI, 2000, p.15).

Confere-se destaque ao discurso, conforme ressalta Maingueneau (2015), como algo amplo e que demanda transformações sociais. Por isso, a transcrição fidedigna da entrevista foi considerada como um texto originário do relato verbal e não-verbal do estudante com $\mathrm{AH}$ ou $\mathrm{SD}$, com a finalidade de compreendê-lo como parte do discurso. Entretanto, considerado como configuração textual, que segundo Mortatti (2000), pode ser entendido como o lugar de sentido e uma representação da realidade, que por meio do diálogo foi o lugar de contestação do outro.

\section{Resultados e discussão}

$\mathrm{Na}$ fala do estudante com AH ou SD foi possível analisar que o ato de entrevistar promoveu a interação entre os sujeitos, por meio da linguagem verbal e não verbal e da constituição do sujeito, naquele momento. De acordo com Charaudeau (2012, p.17) "a linguagem é um objeto não transparente. A linguagem [...] significa o mundo com uma totalidade que inclui o contexto sócio-histórico e as relações que se estabelecem entre os sujeitos". O estudante com AH ou SD demonstrou clareza na elaboração de sua fala, na exposição de suas constatações e no uso da língua. De forma direta, coerente e objetiva explanava suas ideias a cada questionamento, por meio de um vocabulário seleto e formal. Contudo, essa ação foi sendo construída no decorrer da entrevista, visto que o estudante com AH ou SD apresentavase tímido, com certa cautela e buscando uma posição no diálogo, que não o colocasse como público-alvo da Educação Especial.

Essa situação é comum entre pessoas com AH ou SD, tanto que nos estudos de Renzulli (2014; 2018; 2021), o autor discute esse aspecto. Para Renzulli (2014; 2018; 2021), o termo superdotado não pode ser pensado como substantivo, mas como um adjetivo que designará o comportamento, o qual denomina-se superdotado e não a pessoa em si. Nesse sentido, focar nos serviços de atendimento às AH ou SD é mais relevante que trazer para o centro das atenções a pessoa com AH ou SD. Nessa perspectiva, se houver oportunidade haverá engajamento e entusiasmo para a autorrealização da pessoa com AH ou SD. Afinal, a designação para Renzulli (2014; 2018; 2021), tem a função de possibilitar o acesso, no qual a pessoa com $\mathrm{AH}$ ou SD precisa, não a colocando em exposição. 
$\mathrm{O}$ estudante com $\mathrm{AH}$ ou SD falou sobre a dificuldade que encontrou durante parte de sua escolarização realizada em escola pública, devido à ânsia pelo conhecimento, a curiosidade sobre as temáticas abordadas na escola e o entusiasmo em aprender. Sobre esse aspecto Winner (1996, p. 17) teoriza que pessoas com AH ou SD têm a "sede pelo saber ou a fúria por dominar". Para Renzulli (2014; 2018; 2021), tal comportamento apresenta-se como um dos indicadores de AH ou SD, que seria o envolvimento com a tarefa, em contrapartida, evidenciava-se a desmotivação em deparar-se com a realidade financeira de sua família e as condições precárias de ensino e aprendizado ofertadas pela escola pública. Nas palavras do estudante com $\mathrm{AH}$ ou SD:

Eu fui começar a desenvolver - como eu posso dizer! - um maior gosto pela vida acadêmica, quando eu entrei na segunda metade do ensino fundamental. Eu acabei entrando em uma escola particular. Para falar a verdade, foi até uma questão do desenvolvimento do gosto pela faculdade, por qual [curso] eu iria prestar. Eu só fui me decidir mesmo, ao final do terceiro colegial, final do ano passado. Então, foi uma jornada de autoconhecimento, através dessa experiência de vida dentro da escola. Infeližmente, durante a escola pública eu não tive um bom reforço acadêmico. (Estudante com AH ou SD)

Foi esse cenário que fez uma professora inquietar-se com a realidade e a qualidade acadêmica apresentada pelo estudante. A professora o encaminhou via Secretaria da Educação, para um projeto de extensão ocorrido na faculdade pública que acolhia alunos encaminhados de escolas públicas e privadas da cidade, os quais possuíam aspectos que corroboravam com os indicadores de AH ou SD.

Embora o estudante com AH ou SD falasse sobre a melhora de sua autoestima ao ingressar no projeto de extensão, também relatava as atividades que desenvolvia em cada atendimento e a abordagem realizada com os estudantes que participavam do programa sobre o tema das $\mathrm{AH}$ ou $\mathrm{SD}$, como procedimentos para avaliar seu desempenho, expondo a dificuldade em compreender-se como público da Educação Especial e o porquê um aluno com o comportamento dele necessitava de acompanhamento extracurricular. $\mathrm{Na}$ fala do estudante com $\mathrm{AH}$ ou SD foi observado a incompreensão dos termos diagnóstico e identificação, conduzindo a interpretação de que ambos revelam em sua vida um problema. Nas palavras do estudante com AH ou SD:

Eu tive contato com diversas áreas, teste de raciocinio lógico, gramática, conhecimento de línguas estrangeiras. Também, em algumas partes, foi estimulado o conhecimento em grupo, o desenvolvimento de um grupo, em equipe. Essa foi uma parte boa para desenvolver minha parte social. Eu acho que o maior impacto que isso teve na minha formação acadêmica foi por causa desse norte que me deram, com a questão de como o conhecimento poderia me libertar e, pela chance e oportunidade de conseguir ter condições de estudos melhores através do projeto.

Eu sempre via os testes como uma avaliação de desempenho. Eu sei que são vários tipos de quesitos que têm que ser avaliados, mas eu nunca me aprofundei em entender. E eu não sei exatamente quais são os critérios.

Sinceramente, isso para mim nunca fez muita diferença. O diagnóstico para mim é irrelevante, por isso eu nunca esquentei em me identificar.

Para mim o projeto foi mais como uma forma de desafio social, porque eu não estava conseguindo encaixar na escola, mas aqui [referência ao nome da universidade] eu conseguia. (Estudante com $\mathrm{AH}$ ou SD) 
Ressalta-se a importância de falar abertamente com a pessoa com AH ou SD e sua família, caso seja criança ou adolescente, sobre o atendimento educacional e sobre a designação/identificação. É preciso que haja clareza com relação a esse aspecto, de modo que a família se conscientize da magnitude desses atendimentos e colabore com o enriquecimento da pessoa com AH ou SD, bem como possam trabalhar internamente suas expectativas e vaidades frente à condição de seus filhos com AH ou SD (WINNER, 1996). A pessoa com AH ou SD deve ser esclarecida a respeito de sua condição e da importância das ações educativas, as quais lhes são de direito e, assim, tornar-se consciente do processo, colaborando e se posicionando frente a esse cenário.

Para desenvolver e constituir sua identidade torna-se imprescindível para a pessoa com AH ou SD pensar em quem se é de fato, ou seja, olhar para si e na relação com os outros estabelecer pouco a pouco o seu eu. Nas palavras de Duarte (2013, p.15), a esse respeito, “[a] formação do indivíduo para si é a formação do indivíduo como uma pessoa que faz de sua vida uma relação consciente com o gênero humano". As AH ou SD é um fenômeno que se manifesta em alguns seres humanos e em determinados momentos da vida (RENZULLI, 2014), portanto, esse processo de formação do sujeito para si (aquele com a $\mathrm{AH}$ ou SD) se dará mediando o processo de objetivação e apropriação de quem se é, em relação ao meio social. Nesse sentido, será importante estar em meio a seus pares e em programas de enriquecimento, ao mesmo tempo em que também conviva com pessoas que não apresentam as $\mathrm{AH}$ ou SD.

Para o estudante com AH ou SD a precariedade das condições estruturais, de gestão e qualificação docentes eram os problemas identificados por ele na escola pública, bem como o reconhecimento da realidade financeira de sua família, que não teria condições de proporcionar uma escola que atendessem as suas necessidades de desenvolvimento acadêmico. Nesse sentido, a consciência sobre o contexto familiar e escolar que o estudante apresentou demonstrou a resiliência, identificação de suas condições na sociedade, objetividade em suas escolhas e foco em seus objetivos de vida. No entanto, a percepção sobre as $\mathrm{AH}$ ou SD foi compreendida por ele como um problema, visto que utilizou do termo diagnóstico, geralmente empregado em situações da área da Saúde, como referência a esse comportamento. Ao participar do programa de enriquecimento e ter tido acesso ao estudo da temática das $\mathrm{AH}$ ou SD, no âmbito da instrução sobre essa condição, o estudante com AH ou SD demonstrou não compreender a identificação e como esse aspecto contribuiria para o seu desenvolvimento.

Embora demonstre em sua fala consciência sobre o contexto familiar e escolar, ele pode não ter desenvolvido a consciência a respeito do comportamento superdotado. Essa depende do seu entendimento sobre a realidade, que não é constituída somente pela sua percepção e concepção sobre as AH ou SD, mas depende da interação e do diálogo com sujeitos da mesma condição e com profissionais da educação e psicologia, que colaborem na constituição de sua identidade como sujeito com AH ou SD.

Em Benveniste (1988, p. 294) encontra-se que: 
A consciência de si só é possível se experimentada por contraste. Eu não emprego eu a não ser dirigindo-me a alguém, que será na minha alocução um tu. Essa condição de diálogo é que é constitutiva da pessoa, pois implica em reciprocidade — que eu me torne tu na alocução daquele que por sua vez se designa por eu. Vemos aí um princípio cujas consequências é preciso desenvolver em todas as direções. A linguagem só é possível porque cada locutor se apresenta como sujeito, remetendo a ele mesmo como eu no seu discurso. Por isso, o eu propõe outra pessoa, aquela que, sendo embora exterior a "mim", torna-se o meu eco — ao qual digo tu e que me diz tu.

O programa de atendimento a alunos com AH ou SD colaborou para possibilitar o desenvolvimento acadêmico em conjunto com a escolarização. No caso do estudante conseguiu uma bolsa de estudos em uma escola privada. Nesse momento, ele cursava o oitavo ano do ensino fundamental. O estudante com AH ou SD fala sobre o impacto da mudança de escola em sua vida, pois, por um lado era maravilhoso estar em uma instituição de ensino onde era estimulado a estudar e pesquisar sobre diversos temas, por outro lado, a realidade da competição e da desigualdade social era mais evidenciada. O estudante com AH ou SD relata que era tratado por seus colegas de sala como bolsista e sentia a dificuldade de maior socialização, pois, aquele lugar não era pertencente a sua realidade e que estava ali, apenas, por ter conseguido uma bolsa de estudos e não por pertencer àquela realidade econômico-social. Tais aspectos constam no trecho da fala do estudante com AH ou SD:

[...] com relação ao convivio social, infelizmente, eu nunca tive muita sorte. A parte da sociabilidade nunca foi o meu forte. Na escola pública, o pessoal não gostava de mim porque eu era o "sabichão". E na escola particular, como eu tinha bolsa, eu não era o tipo de pessoa que ia nas mesmas festas, que faria as mesmas coisas, que tinha os mesmos jogos... sei lá! Para os jogos. Então, eu nunca consegui me enturmar muito bem. (Estudante com AH ou SD)

Nessa etapa é possível pensar nas teorizações de Dabrowski (2017) ao abordar a Teoria da Desintegração Positiva ${ }^{8}$. Nota-se o conflito interno e a autorreflexão do participante frente a sua condição social versus o ambiente elitizado da escola privada. Ele poderia ficar imóvel, triste e/ou aborrecido diante dessa situação ou, até mesmo, introjetar em si uma realidade elitizada fictícia, mas, pelo contrário, reagiu e seguiu em frente, da melhor maneira que julgou ser possível. Tais aspectos demonstram o comportamento superdotado, pois, o estudante com AH ou SD tem clareza sobre o motivo de seu ingresso na instituição privada de ensino, como o meio a potencializar o seu perfil acadêmico e com o objetivo de conquistar o acesso à Educação Superior em uma instituição pública. O entendimento apresentado pelo aluno com AH ou SD demonstra a inteligência emocional e o foco nessa trajetória, buscando resultar no ingresso em uma universidade pública. Nas palavras do estudante com AH ou SD:

Eu não tive uma boa perspectiva de onde o estudo poderia me levar na escola pública.

Na questão de conteúdo, eu só fui notar a diferença quando eu fui para a escolar particular, por causa

\footnotetext{
${ }^{8}$ Essa teoria apresenta diferentes níveis e caracteriza-se pelo crescimento da estrutura da personalidade de um sujeito. O termo desintegração positiva é utilizado para designar o processo, no qual a personalidade passa a se desenvolver, ou seja, ela se desfaz para se refazer. A desintegração é positiva quando contribui para o crescimento do sujeito e torna-se negativa quando há uma involução (DABROWSKI, 2017).
} 
que a diferença das matérias era bem grande, realmente! Enquanto eu estava na sexta série na escola pública eu não fazia equação. Na escola particular, eu cheguei na sétima tinha equação de segundo grau, Teorema de Tales, um monte de coisa que eu não tinha tido antes. Inclusive, eu demorei uns seis meses para me adequar ao ritmo da turma.

Por causa da condição familiar, eu sempre fui obrigado a prezarpela minha independência. Eu sempre tive que me virar por mim mesmo para certas coisas. Como minha mãe trabalha de noite, durante o dia ela estava sempre dormindo e eu sempre tive que correr atrás dos meus próprios problemas.

Eu tentei pleitear vagas em universidades de fora pelo Sisu [Sistema de Seleção Unificada], mas pela falta de motivação financeira, en tive que desistir (Estudante com AH ou SD)

Durante o período em que estudou na escola pública o estudante com AH ou SD não tinha uma relação amistosa com os colegas e nem com o ambiente, sua ânsia pelo saber era ridicularizada. O estudante relata que na escola pública não tinha um bom reforço acadêmico e quando migrou para a escola privada, percebeu a "doutrinação" na busca pela aprovação em processos seletivos em instituições de Educação Superior pública. Para ele a sociabilidade (termo relatado pelo participante) nunca foi seu forte. O estudante com AH ou SD falou:

\begin{abstract}
Eu sempre tive círculos sociais pequenos.
Infelizmente, durante a escola pública eu não tive um bom reforço acadêmico. Eu não tive uma boa perspectiva de onde o estudo poderia me levar. Eu tive uma maior abrangência do poderio que eu teria com o estudo, na escola particular. Só que eu também... não acho que apesar de ter esse ponto positivo... às vezes é exagerado um pouco nessa parte. Infelizmente, acho que o mecanismo que as escolas particulares têm feito é transformar o aluno em uma máquina de passar em vestibular. Então, apesar de ter esse ponto positivo...eu também... se você não se mantiver acordado, isso acaba impactando psicologicamente, de forma negativa no aluno. (Estudante com AH ou SD)
\end{abstract}

Nesse contexto, o estudante com AH ou SD fala sobre a decisão de focar nos estudos, embora percebesse que em uma escola privada ele estava sendo treinado para fazer processos seletivos para universidades e não, desenvolvendo o seu potencial cognitivo como imaginava anteriormente. A dificuldade de socialização impactava a convivência no âmbito da escola, mas os conteúdos o estimulavam a aprofundar o conhecimento que já deveria ter adquirido e o completavam, devido a ânsia pela aquisição de novos conhecimentos. Chagas-Ferreira (2014) a esse respeito destacaram que pessoas com AH ou SD demonstram preferência pelo isolamento social. Embora, para o estudante com AH ou SD participante dessa pesquisa, a vivência no projeto de extensão que atendia alunos com tais indicativos cooperou para o engajamento social. Também, colaborou para identificar suas possibilidades de ingresso na Educação Superior, na convivência com pares e no reconhecimento do espaço universitário, uma vez que o projeto ocorria em uma faculdade pública. O estudante com AH ou SD enfatizou que considera a faculdade como sua "segunda casa".

Ao finalizar sua escolarização o estudante com AH ou SD teve um novo dilema em sua vida, pois necessitava decidir entre continuar a estudar ou buscar seu primeiro emprego para colaborar com as finanças de sua casa, ao lado de sua mãe. Nas palavras de Chagas e Fleith (2009, p. 156): “[o] microssistema familiar desempenha importante papel mediador na promoção da sobrevivência e da 
socialização, na estrutura de formação da identidade e personalidade e no desenvolvimento dos comportamentos de superdotação".

O estudante com AH ou SD fala sobre o apoio que a mãe ofereceu a ele durante sua escolarização e, em sua participação no programa de acompanhamento a alunos com AH ou SD. Entretanto, a necessidade financeira passa a ser latente em sua fala, possivelmente, pela cobrança de sua mãe sobre a necessidade de ampliar a renda da família. O estudante fala sobre essa situação com expressão triste, mas com a clareza de um sujeito que sabe sobre sua realidade e compreende que a chance de ser aprovado em um processo seletivo para o Educação Superior ocorreria naquele momento de sua vida e, talvez, nunca mais fosse possível. Chagas e Fleith (2009, p.157) ao estudarem casos de AH ou SD em famílias em situação socioeconômica desfavorecida destacaram:

[...] a desigualdade socioeconômica é uma séria barreira para o desenvolvimento das aspirações, talentos e a autorrealização porque essa é permeada por questões ideológicas e políticas que trabalham no sentido de manter o status quo. Sendo assim, as habilidades superiores e o talento de alunos das camadas mais pobres da população ou de certos grupos étnicos tornam-se invisíveis não somente para educadores como para a formulação de políticas e programas de acesso a oportunidades de desenvolvimento do potencial (CHAGAS; FLEITH, 2009, p. 157).

Com todas as circunstâncias relatadas e entendendo o contexto de acesso à Educação Superior, como um momento de profundas mudanças no cotidiano de um jovem, o estudante com AH ou SD não estava fazendo a escolha de aquisição de uma profissão, mas de um futuro melhor. Esse momento de evolução em sua vida familiar poderia ocorrer pelo imediato ingresso no mercado de trabalho ou por um processo mais demorado se escolhido o acesso à Educação Superior. Foi possível constatar na fala do estudante com AH ou SD esse dilema e o imperativo da desigualdade social nesse momento de sua vida. Contudo, o desejo pelo seu desenvolvimento profissional e a ânsia pelo conhecimento o fizeram optar por dar continuidade aos seus estudos. O trecho da fala do estudante com AH ou SD apresenta tais aspectos:

Infelizmente, eu teria que desistirpor um tempo para conseguir um pouco de grana, por causa da minha condição financeira, na época, não iria dar para continuar num cursinho ou coisa do tipo. Eu já estava até me preparando para arranjar um trabalho[...]. Eu tinha refletido. Infelizmente [risos], eu já tinha definido os planos $A, B, C, D$, e E se no caso o plano não desse. (Estudante com AH ou SD)

O estudante com AH ou SD procurava o respeito e o seu lugar na sociedade, queria ocupar seu espaço e não ser visto como alguém que sofre privações, devido à desigualdade social. Ele queria ser alguém que conquistou o seu lugar social e que agregou na sociedade, a esse respeito Rubinstein (1978) afirma que o trabalho/profissão designa e constitui quem se é, ou seja, o papel social. Por esse motivo, a instituição de Educação Superior escolhida não foi uma opção aleatória, pois o estudante com AH ou SD expôs seus critérios, sabia que tinha condições de optar por outras instituições.

Havia conseguido uma elevada pontuação no ENEM (Exame Nacional do Ensino Médio) e poderia fazer a escolha via SISU (Sistema de Seleção Unificada) de uma boa instituição pública, na área 
da Tecnologia da Informação, porém, teria de deixar a cidade onde residia, condição inviável por questões financeiras. Nesse sentido, a opção de curso restringia-se a uma instituição pública na cidade onde residia e fora da área que, incialmente, havia se identificado. Esse processo de escolha demonstrou o entendimento do estudante com AH ou SD sobre suas condições de vida, apresentando a consciência, resiliência, paciência e, sobretudo, transgressão, quando compreende como poderia continuar seus estudos - o que era seu maior desejo - em condições opostas a realidade vivenciada em toda sua trajetória de vida.

Ao optar por ingressar na Educação Superior o estudante com AH ou SD é acometido por duas circunstâncias, sendo a primeira a oportunidade de mudança de sua vida financeira, pela aquisição de uma profissão e a segunda, a sua identificação como uma pessoa com AH ou SD, que poderia maximizar essa oportunidade e colaborar para conquistar patamares que o auxiliassem a adquirir uma fonte de renda, ainda que fosse um estudante. Nesse contexto, o estudante com AH ou SD conquistaria argumentos para mostrar a sua mãe a importância do acesso à Educação Superior e a concretização de melhores oportunidades em sua vida. Oliveira, Rodrigues e Capellini (2020) constataram em análise de teses e dissertações brasileiras sobre $\mathrm{AH}$ ou SD, carência de estudos que investiguem essa temática na Educação Superior. Contudo, apresentaram a busca pela identificação desses estudantes com AH ou SD nesse nível de ensino e o recente interesse dos pesquisadores por tal fato.

O conhecimento desperta no estudante com AH ou SD a coragem e direciona suas ações para vencer as dificuldades da vida. A identificação como pessoa com AH ou SD, nesse momento, não o auxilia em termos de condição de acesso pela Lei Brasileira de Inclusão - LBI nº 13.146/2015 (BRASIL, 2015), devido a faculdade não possuir oferta alguma de atendimento a esse público. No entanto, são as condições cognitivas, emocionais e de interpretação do contexto as características fomentadoras do desenvolvimento de sua consciência e compreensão de suas condições de vida. O estudante com AH ou SD falou:

Refleti muito sobre a minha condição de vida e a vontade de ingressar na Educasãa Superior e, infelizmente, fiz vários planos tentando projetar os cenários que poderia enfrentar. Ainda, no dia do processo seletivo, tive problemas pessoais, que quase me fizeram perder a prova. (Estudante com $\mathrm{AH}$ ou SD)

O estudante com $\mathrm{AH}$ ou SD relatou que até sair o resultado do processo seletivo, ele ficou angustiado e isolado. Quando o resultado saiu estava em lista de espera, achou que não teria mais chances e foi retirar sua carteira de trabalho. Por meio da intervenção do projeto de extensão que atendia alunos com características de $\mathrm{AH}$ ou $\mathrm{SD}$, ele conseguiu compreender que tinha ainda a oportunidade de ingresso pela segunda opção de curso, no processo seletivo. Para ingressar na faculdade, o estudante com AH ou SD ficou dois meses no curso de sua segunda opção. Quando soube que seria possível ingressar na faculdade, o estudante com AH ou SD falou sobre a euforia em ter conseguido acessar a Educação Superior em uma instituição pública, na cidade onde residia. Nota-se a representação de uma instituição 
pública de Educação Superior em sua vida e o seu entendimento sobre o que representa na sociedade e na formação profissional. Além da consciência sobre o retorno à sociedade que esse tipo de instituição de ensino confere.

Após dois meses de aula, o estudante com AH ou SD foi chamado para ingressar no curso de sua primeira opção no processo seletivo. Ele relata que foi difícil, porque estava gostando do curso, mas a primeira opção foi uma escolha consciente, em relação ao percurso profissional que ele almejava. Destacou ainda na entrevista, a vontade de retomar o curso de segunda opção em algum momento de sua vida. Por meio da fala do estudante com AH ou SD foi perceptível o prazer pelo aprender, em qualquer que seja o contexto e foco profissional, algo que pesquisadores como Winner (1996) e Renzulli $(2014 ; 2018 ; 2021)$ constataram em suas pesquisas.

Ao ingressar no curso superior, o estudante relatou que teve contato com um amigo da época da escola, porém enfatizou a preferência por desenvolver suas atividades acadêmicas sozinho. $\mathrm{O}$ estudante falou que:

No comeso tive que entrar em um grupo de trabalho e foi muito ruim, porque eles tiveram que se adequar para me receber. Eu colaborei com o grupo, mas não me sent [i] parte dele.

Não me envolvo muito com os colegas. Não tenho laços de amizade [expressa inferioridade]. Um amigo entra na esfera privada. É necessário ter confiança. (Estudante com AH ou SD)

Outro momento desafiador vivenciado pelo estudante com AH ou SD e relacionado a sua permanência na Educação Superior foi o descompasso gerado no ingresso em um curso que já estava em andamento. O estudante relatou que se sentiu desanimado, pois havia perdido oportunidades de entrar em determinados grupos de estudo, extensões e comitês que possuem eleições ou processos seletivos para o ingresso. Também, expressou preocupação por se tratar de oportunidades vinculadas ao início da turma, não sendo possível recuperá-las posteriormente, entretanto, não se acomodou e buscou novas oportunidades. O estudante com AH ou SD falou:

Não me deixei abater! Arrumei outras coisas para fazer no lugar, com o mesmo nivel. Fui conversando com outros alunos e descobrindo como era. Corri atrás dos professores e teve uma professora que me ajudou a entender como completar as horas complementares e horas de estágio. (Estudante com $\mathrm{AH}$ ou SD)

Outro aspecto importante foi a persistência do estudante com AH ou SD em permanecer na faculdade pública, pois, mesmo sendo aberto o acesso à Educação Superior pública, existem custos para manter-se em uma graduação. Nesse sentido, o estudante tinha gastos com transporte, alimentação, materiais de estudos, participação em cursos e eventos de sua área de formação. Por esse cenário, o estudante com AH ou SD recorreu ao processo seletivo do programa de permanência estudantil, no qual conquistou uma bolsa no valor de meio salário-mínimo. Foi por meio desse valor que conseguiu manterse no primeiro semestre da graduação. Ao ingressar no curso de sua primeira opção foi atendido o seu objetivo de formação profissional, incialmente, planejado por ele. 
Contudo, a bolsa de permanência seria insuficiente para cumprir as demandas de formação dessa graduação. Assim buscou junto aos grupos de pesquisa, uma oportunidade de bolsa de pesquisa e conquistou um fato raro para alunos de primeiro ano: conseguiu uma bolsa relacionada a empresa júnior mantida na faculdade para atender interesses de empresas da cidade, relacionadas ao comércio exterior.

Apesar da coleta dos dados ter ocorrido no primeiro ano, pois o foco do estudo seria sobre o ingresso de estudantes com $\mathrm{AH}$ ou SD na Educação Superior, foram apontadas pelo estudante dificuldades de compreensão de sua identificação, bem como o impacto da desigualdade social mesmo para uma pessoa com AH ou SD. Tais indicativos possibilitaram sua compreensão sobre as barreiras, principalmente, atitudinais, mas não diretamente relacionadas às $\mathrm{AH}$ ou SD.

Essas circunstâncias foram promovidas pelas condições de desigualdade social e em seu caso, os indicativos de $\mathrm{AH}$ ou SD foram imprescindíveis para vencer todas as dificuldades impostas pelo meio social, educacional e familiar ao ingresso na Educação Superior. As palavras do participante exemplificam os achados de Guenther $(2007 ; 2011 ; 2012)$. As condições socioeconômicas são mais complexas que a condição de pessoa com AH ou SD, pois limitam o acesso, o sonho e as oportunidades das pessoas. $\mathrm{O}$ Brasil, de acordo com Guenther (2007; 2011; 2012) é de longa data desigual e, por isso, projetos, Organizações Não-Governamentais (ONGs) e as escolas são importantes para ajudar as pessoas com AH ou SD em situação de vulnerabilidade social, como forma de possibilitar o acesso de que precisam. Para Guenther $(2007 ; 2011 ; 2012)$ é necessária a preocupação com crianças e jovens com AH ou SD em situação de vulnerabilidade social e econômica, pois é preciso atendê-los, ao contrário de ficar refém das burocracias e/ou discutindo o que pode ou não pode ser feito. Esses jovens não podem esperar pelo atendimento educacional que suplemente suas necessidades educativas. É preciso que os professores sejam instruídos sobre a identificação (GUENTHER, 2012; CIANCA; MARQUEZINE, 2014; OLIVEIRA; RODRIGUES; CAPELLINI, 2020; RENZULLI, 2021).

Destaca-se a ausência de suporte e/ou estratégia para atender o estudante com AH ou SD na Educação Superior, demonstrando que o êxito obtido por ele decorreu de seu esforço desmedido para conseguir, seja de natureza cognitiva e psicológica, cumprir esse percurso. Além da menção a uma professora, que o auxiliou como cumprir alguns requisitos do trajeto acadêmico, não houve na fala do estudante com $\mathrm{AH}$ ou SD, outro momento em que tais indicativos fossem aproveitados para o seu desenvolvimento e da própria comunidade acadêmica. Cianca e Marquezine (2014) entrevistaram 14 coordenadores dos colegiados dos cursos de licenciatura da Universidade Estadual de Londrina - UEL com o objetivo de identificar a percepção desses sobre a temática das AH ou SD. A percepção dos docentes indicou a presença do senso comum a respeito das AH ou SD e a dificuldade em identificar em seus alunos o potencial para AH ou SD, embora destacassem a presença de indicadores ao exemplificar situações vivenciadas em sala de aula. 


\section{Considerações finais}

Em síntese observamos o atraso no cumprimento das políticas referentes à inclusão na Educação Superior para pessoas com AH ou SD, o descaso educacional referente à existência dessas pessoas e suas necessidades de aprendizado, bem como compreensão do fenômeno pautada pelo senso comum por parte dos educadores. Também, destacam-se o preconceito por parte dos colegas e as dificuldades socioeconômicas, as quais constituíram desafios para o participante ingressar no Educação Superior e conseguir permanecer. Enfatizam-se a inteligência emocional e a capacidade acadêmica, principalmente, o senso de lógica e objetividade, que deram ao participante estruturação e força para suportar as dificuldades em sua vida. Ressalta-se sua resiliência e paciência para esperar a hora certa e o momento oportuno para a realização de suas escolhas.

A universidade escolhida pelo participante reforça e exemplifica o atraso no atendimento a pessoas com $\mathrm{AH}$ ou $\mathrm{SD}$, pois o estudante poderia não somente estar sendo atendido pelo Núcleo de Acessibilidade e Inclusão, como usufruindo do processo de aceleração do curso, ou em alguma iniciativa, desenvolvendo um projeto de pesquisa de sua escolha ou alguma programação que pudesse suplementar e enriquecê-lo. No entanto, buscou de forma individual, se enriquecer por meio das oportunidades existentes, contando com o acaso para colocá-lo diante de pessoas importantes, que o estão ajudando. Entretanto, é possível questionar: até quando as oportunidades serão fruto do acaso, da sorte ou do extremo esforço pessoal, no contexto das AH ou SD na Educação Superior?

A necessidade do acolhimento, identificação dos estudantes com AH ou SD, aprofundamento das relações professor - estudante, bem como da comunidade acadêmica são aspectos que precisam ser refletidos. Além disso, o resultado dessas reflexões deve impactar novas formas organizacionais, de gestão administrativa e acadêmica das instituições de Educação Superior. Essa nova trajetória poderia romper com o ensino bancário, expositivo e técnico da Educação Superior, para uma trajetória de formação profissional que preze pelo desenvolvimento humano. Há necessidade de identificação do estudante com AH ou SD, de forma que a Educação Superior seja capaz de sistematizar um ensino inclusivo, que atenda às necessidades educacionais das pessoas com $\mathrm{AH}$ ou $\mathrm{SD}$, não permitindo que essas dependam, apenas, de esforços individuais ou familiares. 


\section{REFERÊNCIAS}

BASSO, Eduarda et al. Identificação de estudantes com Altas Habilidades/Superdotação no Ensino superior. Rev. Bras. Ed. Esp., Bauru, v.26, n.3, p.453-464, Jul.-Set., 2020. Disponível em:

https://www.scielo.br/j/rbee/a/NYTWRyzvcHxYPQLVB6qcRtj/?lang=pt. Acesso em: 15 jan. 2021.

BENVENISTE, Émile. Da subjetividade na linguagem. In: BENVENISTE, Émile. Problemas de Linguística Geral I. 2. ed. Campinas: Editora da Unicamp; Pontes, 1988. p. 284-293.

BRASIL. Ministério da Educação. Lei de Diretriz̧es e Bases da Educação Nacional. Brasília, 20 de dezembro de 1996. Disponível em: http://www.planalto.gov.br/ccivil 03/leis/19394.htm. Acesso em: 08 fev. 2021.

BRASIL. Lei no 13.146, de 6 de julho de 2015. Lei Brasileira de Inclusão - LBI. Diário oficial [da] República Federativa do Brasil, Brasília, DF, 7 jun. 2015. Disponível em: http://www.planalto.gov.br/ccivil 03/ Ato2015-2018/2015/Lei/L13146.htm. Acesso em: 10 jan. 2021.

CIANCA, Fabiane Silva Chueire; MARQUEZINE, Maria Cristina. A percepção dos coordenadores de licenciaturas da UEL sobre Altas Habilidades/ Superdotação. Rev. Bras. Ed. Esp., Marília, v. 20, n. 4, p. 591-604, Out./Dez., 2014. Disponível em: http://dx.doi.org/10.1590/S1413-65382014000400010. Acesso em 08 fev. 2021.

CHARAUDEAU, Patrick. Linguagem e discurso: modos de organização. Trad. Angela Corrêa e Ida Machado. 2. ed. São Paulo: Contexto, 2012, 256 p.

CHAGAS, Jane Farias; FLEITH, Denise de Souza. Estudo comparativo sobre superdotação com famílias em situação socioeconômica desfavorecida. Rev. Bras. Ed. Esp., Marília, v.15, n.1, p.155-170, jan.-abr. 2009. Disponível em:

https://www.scielo.br/j/rbee/a/sH696Yb5XhyXn7nnFSjbfwf/abstract/?lang=pt. Acesso em: 10 jan. 2021.

CHAGAS-FERREIRA, Jane. Farias. As características socioemocionais do indivíduo talentoso e a importância do desenvolvimento de habilidades sociais. In: VIRGOLIM, Angela; KONKIEWITZ, Elizabete. Castelon. (orgs.). Altas Habilidades/Superdotação, inteligência e criatividade: uma visão muldisciplinar. Campinas: Papirus, 2014, p. $99-118$.

DABROWSKI, Kazimierz. Positive disintegration. Estados Unidos: Maurice Bassett, 2017, 130p.

DUARTE, Newton. A individualidade para si. 3. ed. Campinas: Autores Associados. 2013, p. 254.

FARIAS, Elaine Santos de. S.; WESCHLER, Solange Muglia. Desafios na identificação de alunos intelectualmente dotados. In: VIRGOLIM, Angela; KONKIEWITZ, Elizabete Castelon. (Orgs). Altas Habilidades/Superdotação, inteligência e criatividade: uma visão muldisciplinar. Campinas: Papirus, 2014, p. $335-350$.

FREITAS, Soraia Napoleão; PÉREZ, Susana Graciela Pérez Barrera. Altas Habilidades/Superdotação: atendimento especializado. Marília: ABPEE, 2012. 140 p.

GUENTHER, Zenita Cunha. Centros comunitários para desenvolvimento de talentos - O CEDET. Revista Educação Especial. Santa Maria, v 1, n. 30, 2007, p. 1-9. Disponível em: https://periodicos.ufsm.br/educacaoespecial/article/view/4054. Acesso em: 01 abr. 2021. 
GUENTHER, Zenita Cunha. Caminhos para desenvolver potencial e talento. Lavras: Ed. UFLA, 2011. 220p.

GUENTHER, Zenita Cunha. Quem são os alunos dotados? Reconhecer dotação e talento na escola. In: MOREIRA, Laura Ceretta; STOLTZ, Tania. (orgs.). Altas habilidades/superdotação, talento, dotação e educação. Curitiba: Juruá, 2012, p. 63 - 94.

LIMA, Denise Maria de Matos; MOREIRA, Laura Ceretta. O professor frente à identificação do estudante com altas habilidades/superdotação na universidade. In: VIRGOLIM, Angela. (orgs.). Altas Habilidades/Superdotação: processos criativos, afetivos e desenvolvimento de potenciais. Curitiba: Juruá, 2018, p. 19 - 42.

LÜDKE, Menga; ANDRÉ, Marli Eliza Dalmaso Afonso de. Pesquisa em Educação: abordagens qualitativas. São Paulo: EPU, 1986. 99p.

MAINGUENEAU, Dominique. Discurso e análise do discurso. Tradução de Sírio Possenti. São Paulo: Parábola Editorial, 2015. 192 p.

MANZINI, Eduardo José. Análise de entrevista. Marília: ABPEE, 2020. 284p.

MARCUSCHI, Luiz Antônio. Análise da conversação. São Paulo: Ática, 1986. 94p.

MORTATTI, Maria do Rosário L. Os sentidos da Alfabetização. São Paulo: Editora Unesp, 2000. 372p.

NAKANO, Tatiana de Cassia. Avaliação psicométrica das habilidades cognitivas: relação entre inteligência e criatividade. In: VIRGOLIM, Angela; KONKIEWITZ, Elisabete Castelon (orgs.). Altas Habilidades/Superdotação, inteligência e criatividade: uma visão multidisciplinar. Campinas: Papirus, 2014, p. $99-118$.

OLIVEIRA, Ana Paula; RODRIGUES, Olga Maria Piazentin Rolin; CAPELLINI, Vera Lucia Messias Fialho. Altas Habilidades / Superdotação no ensino superior: análise de dissertações e teses brasileiras. Psicologia Escolar e Educacional. São Paulo, v. 24, p. 1 -7, 2020. Disponível em:

https://www.scielo.br/i/pee/a/MtVWX4vsdBQLYC7LjdY6SbL/?lang=pt. Acesso em: 09 jan. 2021.

OLIVEIRA, Ana Paula Santos. Identificação de Altas Capacidades em estudantes estrangeiros no ensino superior. 2020. 91 f. Dissertação (Mestrado em Educação Especial) - Universidade Federal de São Carlos, São Carlos, 2020. Disponível em: https://repositorio.ufscar.br/handle/ufscar/12459?show=full. Acesso em: 20 jan. 2021.

RENZULLI, Joseph. A concepção de superdotação no modelo dos três anéis: um modelo de desenvolvimento para a promoção da produtividade criativa. In: VIRGOLIM, Angela; KONKIEWITZ, Elisabete Castelon (orgs.). Altas Habilidades/Superdotação, inteligência e criatividade: uma visão multidisciplinar. Campinas: Papirus, 2014, p. 219 - 264.

RENZULLI, Joseph. Reexaminando o papel da educação para superdotados e o desenvolvimento de talentos para o século XXI: uma abordagem teórica em quatro partes. In: VIRGOLIM, A. (org.). Altas Habilidades/Superdotação: processos criativos, afetivos e desenvolvimento de potenciais. Curitiba: Juruá, 2018, p. 19 - 42.

RENZULLI, Joseph. Reflections on my work: the identification and development of creative/productive giftedness. In: DAI, David Yun; STERNBERG, Robert Jeffrey (Eds.). Scientific Inquiry Into Human Potencial: historical and contemporary perspectives across disciplines. Estados Unidos: Routledge, 2021, p. 197-211. 
RENZULLI, Joseph; REIS, Sally. The schoolwide enrichment model: a comprehensive plan for education excellence. 3. ed. Connecticut: Creative Learning Press, 2014.

RUBINSTEIN, Sergei Leontiev. Princípios da Psicologia Geral. Barcelona: Editorial Grijalbo, 1978, p. 767.

SOUZA, Sérgio Augusto Freire de. Análise de discurso: procedimentos metodológicos. Manaus: Instituto Census, 2014. 57p.

VIGOTSKI, Lev Semionovitch. Pensamento e linguagem. Tradução Jéferson Luiz Camargo. São Paulo: Martins Fontes, 1989. 496p.

WINNER, Ellen. Crianças sobredotadas. Portugal: Instituto Piaget, 1996, 383p.

YIN, Robert K. Estudo de caso: planejamento e métodos. Tradução Ana Thorell. Revisão técnica Cláudio Damacena. 4. ed. Porto Alegre: Bookman, 2010. 248p. 